\title{
A Prognostic Merit of Statins in Patients with Chronic Hemodialysis after Percutaneous Coronary Intervention-A 10-Year Follow-Up Study
}

\author{
Takehiro Funamizu ${ }^{1}$, Hiroshi Iwata ${ }^{1, * \mathbb{D}}$, Yuichi Chikata ${ }^{1}$, Shinichiro Doi ${ }^{1}$, Hirohisa Endo ${ }^{1}$, Hideki Wada ${ }^{2}$, \\ Ryo Naito ${ }^{1}$, Manabu Ogita ${ }^{2} \mathbb{D}$, Yoshiteru Kato ${ }^{1}$, Iwao Okai ${ }^{1}$, Tomotaka Dohi ${ }^{1} \mathbb{D}$, Takatoshi Kasai ${ }^{1}{ }^{1 D}$, \\ Kikuo Isoda $^{1}{ }^{\mathbb{D}}$, Shinya Okazaki ${ }^{1}$, Katsumi Miyauchi ${ }^{1}$ and Tohru Minamino ${ }^{1}$ \\ 1 Department of Cardiovascular Biology and Medicine, Juntendo University Graduate School of Medicine, \\ Tokyo 113-8421, Japan; t-funamizu@juntendo.ac.jp (T.F.); ychikata@juntendo.ac.jp (Y.C.); \\ doies@juntendo.ac.jp (S.D.); hendo@juntendo.ac.jp (H.E.); rnaitou@juntendo.ac.jp (R.N.); \\ y-0104@juntendo.ac.jp (Y.K.); okaiwao@juntendo.ac.jp (I.O.); tdohi@juntendo.ac.jp (T.D.); \\ tkasai@juntendo.ac.jp (T.K.); kisoda@juntendo.ac.jp (K.I.); shinya@juntendo.ac.jp (S.O.); \\ ktmmy@juntendo.ac.jp (K.M.); t.minamino@juntendo.ac.jp (T.M.) \\ 2 Department of Cardiology, Juntendo University Shizuoka Hospital, Izunokuni 410-2295, Japan; \\ hdwada@juntendo.ac.jp (H.W.); m-ogita@juntendo.ac.jp (M.O.) \\ * Correspondence: hiroiwata-circ@umin.ac.jp; Tel.: +81-3-3813-3111
}

check for updates

Citation: Funamizu, T.; Iwata, H.; Chikata, Y.; Doi, S.; Endo, H.; Wada, H.; Naito, R.; Ogita, M.; Kato, Y.; Okai, I.; et al. A Prognostic Merit of Statins in Patients with Chronic Hemodialysis after Percutaneous Coronary Intervention-A 10-Year Follow-Up Study. J. Clin. Med. 2022, 11, 390. https://doi.org/10.3390/ jcm11020390

Academic Editors: Adrian Covic, Alexandru Burlacu and Francesco Giallauria

Received: 3 December 2021 Accepted: 9 January 2022

Published: 13 January 2022

Publisher's Note: MDPI stays neutral with regard to jurisdictional claims in published maps and institutional affiliations.

Copyright: (C) 2022 by the authors. Licensee MDPI, Basel, Switzerland. This article is an open access article distributed under the terms and conditions of the Creative Commons Attribution (CC BY) license (https:// creativecommons.org/licenses/by/ $4.0 /)$.

\begin{abstract}
Background: Patients with end-stage renal disease (ESRD) on chronic hemodialysis who are complicated by coronary artery disease (CAD) are at very high risk of cardiovascular (CV) events and mortality. However, the prognostic benefit of statins, which is firmly established in the general population, is still under debate in this particular population. Methods: As a part of a prospective single-center percutaneous coronary intervention (PCI) registry database, this study included consecutive patients on chronic hemodialysis who underwent PCI for the first time between 2000 and 2016 ( $n=201)$. Participants were divided into 2 groups by following 2 factors, such as (1) with or without statin, and (2) with or without high LDL-C ( $>$ and $\leq$ LDL-C $=93 \mathrm{mg} / \mathrm{dL}$, median) at the time of PCI. The primary endpoint was defined as CV death, and the secondary endpoints included all-cause and non-CV death, and 3 point major cardiovascular adverse events (3P-MACE) which is the composite of $\mathrm{CV}$ death, non-fatal myocardial infarction and stroke. The median and range of the follow-up period were 2.8, 0-15.2 years, respectively. Results: Kaplan-Meier analyses showed significantly lower cumulative incidences of primary and secondary endpoints other than non-CV deaths in patients receiving statins. Conversely, no difference was observed when patients were divided by the median LDL-C at the time of PCI $(p=0.11)$. Multivariate Cox proportional hazard analysis identified statins as an independent predictor of reduced risk of CV death (Hazard ratio of statin use: $0.43,95 \%$ confidence interval $0.18-0.88, p=0.02$ ), all-cause death (HR: $0.50,95 \% \mathrm{CI}$ $0.29-0.84, p=0.007$ ) and 3P-MACE (HR: 0.50, 95\%CI 0.25-0.93, $p=0.03$ ). Conclusions: Statins were associated with reduced risk of adverse outcomes in patients with ESRD following PCI.
\end{abstract}

Keywords: hemodialysis; statin; secondary prevention; percutaneous coronary intervention; cardiovascular death

\section{Introduction}

In accordance with the increase of the global prevalence of chronic kidney disease (CKD) as a major healthcare burden worldwide [1], the number of patients with end stage renal disease (ESRD) requiring chronic renal replacement therapy, including hemodialysis, peritoneal dialysis and functioning kidney transplantation, has significantly increased over time $[2,3]$. Among patients with CKD, which is associated with substantially higher cardiovascular (CV) mortality and morbidity rates [4], those on chronic hemodialysis are at particularly very high risk of all-cause as well as CV mortality [5]. In patients on chronic 
hemodialysis, coronary artery disease (CAD) is a major concern due to its substantially high prevalence at the induction of maintenance hemodialysis therapy [6]. Patients on hemodialysis and with established CAD following percutaneous coronary intervention (PCI) are much more prone to subsequent repeated revascularization and CV death [7]. Therefore, optimal medications for secondary prevention of CV events are critically important in patients with both chronic hemodialysis and CAD. The accumulating evidence has obviously indicated the effectiveness of statins in the primary and secondary prevention of $\mathrm{CV}$ diseases in diverse high-risk populations, such as CKD patients [8]. However, three previous landmark randomized trials involving patients with maintenance hemodialysis [9-11] have failed to show the benefit of statins at reducing the risk of cumulative CV events and all-cause mortality, and current guidelines have not recommended the initiation of statins for hemodialysis patients [12]. Nevertheless, since these studies did not include many patients having both ESRD on dialysis and CAD, the merit of statins is still open to question in such particular population.

Therefore, the aim of this observational study involving patients in a prospective PCI registry database was to explore in detail whether statin therapy was associated with a reduced risk of adverse $\mathrm{CV}$ outcomes in hemodialysis patients following PCI.

\section{Materials and Methods}

This study was performed in accordance with the Declaration of Helsinki and with approval from the Institutional Review Board (IRB) of Juntendo University (IRB number: 17-170). The prospective registry database of patients who underwent any PCI at Juntendo University Hospital, Tokyo, Japan (Juntendo Physicians' Alliance for Clinical Trial: J-PACT) is publicly registered (University Medical Information Network Japan-Clinical Trials Registry, UMIN-CTR 000035587). Written informed consent was obtained from all participants for the J-PACT registry.

\subsection{Participants and Follow-Up Duration}

2.1.1. Participants

This study is a retrospective analysis of a portion of a prospective single-center registry database of patients who underwent PCI at Juntendo University Hospital. The database was launched in February 1984 (Juntendo Physicians' Alliance for Clinical Trial, J-PACT). The registry database includes data regarding patient demographics, coronary artery lesions, PCI procedures, and devices used during the procedure. Patients who underwent any type of percutaneous coronary artery intervention procedure, including thrombectomy, balloon angioplasty, and/or deployment of any type of coronary stent, were enrolled in the registry. In the study period between 2000 and 2016, consecutive 4542 patients who underwent PCI for the first time were registered in the database. After excluding patients without maintenance hemodialysis at PCI $(n=4341)$, the remaining 201 patients were enrolled in the present study. Patients with ESRD who underwent temporary hemodiafiltration and peritoneal dialysis were excluded. Thereafter, we divided the participants into 2 groups according to whether they did or did not receive statins at PCI (Statin group and Non-statin group, $n=73$ and $n=128$, respectively) (Supplementary Figure S1). Blood samples were collected in the early morning after overnight fasting.

\subsubsection{Follow-Up}

In this prospective PCI registry database, the follow-up of patients was based on chart review, as far as they were followed at Juntendo University Hospital. A prognosis survey questionnaire was mailed out every 5 years if they were transferred to other institutions. When there was no response to the questionnaire, further follow-up information was obtained by telephone. In cases in which no response could be obtained by either mail and phone, follow-up was terminated at the latest time point at which their survival at our institution was confirmed, such as the last visit date to an outpatient clinic or the last day 
of any hospitalization. The median and range of the follow-up period since the index PCI were 2.8 and $0-15.2$ years, respectively.

\subsubsection{Endpoints}

The primary endpoint set in the present study was CV death, which was defined as a composite of the following types of death; sudden death in which non-cardiac death could not be excluded, and death due to myocardial infarction, heart failure, cardiogenic shock, a cerebrovascular event, or aortic diseases. The secondary endpoints included allcause death, mortality other than cardiovascular-related (non CV death) and 3 point major adverse cardiovascular events (3P-MACE) defined as a composite of CV death, non-fatal myocardial infarction, and non-fatal stroke [13].

\subsection{Statistical Analysis}

Continuous variables are presented as the mean \pm standard deviation or median with interquartile range (IQR) in accordance with the results of the Shapiro-Wilk normality test. Categorical variables are presented as the actual number and frequencies (\%). Quantitative data across groups were compared using the ANOVA test or the Kruskal-Wallis test. Categorical variables were compared using the Fisher-exact test with the chi-squared test. Unadjusted Kaplan-Meier analysis evaluated the time to the cumulative CV mortality, all-cause mortality, 3P-MACE, and non-CV mortality followed by the log-rank test for comparisons. The prognostic impact of statins at PCI on CV death, all-cause death and 3P-MACE were assessed by univariate and multivariate Cox proportional hazards regression analyses calculating hazard ratios (HR) with 95\% confidence intervals (CI) for three endpoints. For multivariate analyses, covariates other than statin therapy at PCI were selected based on the findings of baseline characteristics and univariate unadjusted analyses in addition to previously established factors associated with vital consequences in this population, such as age, gender and diabetic nephropathy [14,15]. Covariates used in 3 models are summarized in Supplementary Table S1. Model 1 included age, gender, BMI and diabetic nephropathy in addition to statin therapy. Model 2 had beta-blockers and LDL-C level in addition to the covariates in Model 1, and Model 3 had hs-CRP in addition to the covariates of Model 2. Age, BMI, LDL-C and hs-CRP were assessed as continuous variables in all models. In multivariate Cox proportional hazard models, interactions amongst statin therapy and LDL-C levels were assessed (Supplementary Table S2). A $p$-value $(p)<0.05$ was considered to indicate statistical significance. Statistical analyses were performed using JMP version 12.1 (SAS Institute, Cary, NC, USA) and SPSS version 26 (IBM Corp., Armonk, NY, USA).

\section{Results}

\subsection{Baseline Demographics and Procedural Characteristics}

The present study included 201 patients with chronic hemodialysis who underwent PCI. The mean age was $66.0 \pm 10.3$ years, and the median duration of hemodialysis was 5.2 years. Statins were prescribed in 73 patients (36.3\%) (Statin group) and not prescribed in 128 patients (Non-statin group). In the statin group, 51 (69.9\%) received low-intensity and $22(30.1 \%)$ moderate-intensity statins, while none received high-intensity statins according to the guidelines, atorvastatin $40-80 \mathrm{mg} /$ day and rosuvastatin $20-40 \mathrm{mg} /$ day $[16,17]$. The baseline and procedural characteristics are listed and compared in Table 1.

Both groups were similar in most of the demographic and procedural factors, except for a significantly lower proportion of males and lower LDL-C levels in the Statin group.

There were no significant differences between the groups regarding medications, including beta-blockers, calcium channel blockers (CCBs), angiotensin converting enzyme (ACE) inhibitors, and angiotensin receptor blockers (ARB). 
Table 1. Baseline clinical characteristics of the study population.

\begin{tabular}{|c|c|c|c|c|}
\hline & $\begin{array}{c}\text { Overall } \\
(n=201)\end{array}$ & $\begin{array}{l}\text { Statin } \\
(n=73)\end{array}$ & $\begin{array}{l}\text { Non-Statin } \\
(n=128)\end{array}$ & $p$-Value \\
\hline $\mathrm{BMI}^{1}, \mathrm{~kg} / \mathrm{m}^{2}$ & $22.4 \pm 3.9$ & $22.6 \pm 4.3$ & $22.3 \pm 3.6$ & 0.67 \\
\hline Age, years & $66.0 \pm 10.3$ & $65.2 \pm 11.9$ & $66.6 \pm 9.3$ & 0.35 \\
\hline Male, $n(\%)$ & $168(83.6)$ & $56(76.7)$ & $112(87.5)$ & 0.047 \\
\hline Hypertension, $n(\%)$ & $174(86.6)$ & $60(82.2)$ & $114(89.1)$ & 0.17 \\
\hline Dyslipidemia, $n(\%)$ & $156(77.6)$ & $73(100)$ & $83(64.8)$ & $<0.001$ \\
\hline Diabetic nephropathy, $n(\%)$ & $123(61.2)$ & $44(60.3)$ & $79(61.7)$ & 0.84 \\
\hline Duration of hemodialysis (years) & $5.2(1.6-10.0)$ & $4.0(1.2-8.9)$ & $5.4(1.9-10.9)$ & 0.20 \\
\hline History of smoking, $n(\%)$ & $118(58.7)$ & $39(53.4)$ & $79(61.7)$ & 0.25 \\
\hline Family history, $n(\%)$ & $46(22.9)$ & $15(20.6)$ & $31(24.2)$ & 0.55 \\
\hline Atrial fibrillation, $n(\%)$ & $26(12.9)$ & $8(11.0)$ & $18(14.1)$ & 0.53 \\
\hline Prior $\mathrm{PCI}^{2}, n(\%)$ & $39(19.5)$ & $14(19.2)$ & $25(19.7)$ & 0.93 \\
\hline Prior myocardial infarction, $n(\%)$ & $44(21.9)$ & $17(23.3)$ & $27(21.1)$ & 0.72 \\
\hline Prior $\mathrm{CABG}^{3}, n(\%)$ & $38(18.9)$ & $12(16.4)$ & $26(20.3)$ & 0.50 \\
\hline Peripheral arterial disease, $n(\%)$ & $55(27.4)$ & $21(28.8)$ & $34(26.6)$ & 0.74 \\
\hline Prior cerebrovascular disease, $n(\%)$ & $34(16.9)$ & $11(15.1)$ & $23(18.0)$ & 0.60 \\
\hline $\mathrm{ACS}^{4}, n(\%)$ & $36(17.9)$ & $12(16.4)$ & $24(18.8)$ & 0.68 \\
\hline Number of vessels & $2.1 \pm 0.8$ & $2.0 \pm 0.8$ & $2.1 \pm 0.8$ & 0.49 \\
\hline $\mathrm{RCA}^{5}, n(\%)$ & $74(36.8)$ & $27(37.0)$ & $47(36.7)$ & 0.97 \\
\hline $\mathrm{LAD}^{6}, n(\%)$ & $80(39.8)$ & $28(38.4)$ & $52(40.6)$ & 0.75 \\
\hline $\mathrm{LCX}^{7}, n(\%)$ & $38(18.9)$ & $15(20.6)$ & $23(18.0)$ & 0.65 \\
\hline $\mathrm{LMT}^{8}, n(\%)$ & $7(3.5)$ & $2(2.7)$ & $5(3.9)$ & 1.00 \\
\hline $\mathrm{SVG}^{9}, n(\%)$ & $2(1.0)$ & $1(1.4)$ & $1(0.8)$ & 1.00 \\
\hline Stent diameter, $\mathrm{mm}$ & $3.0 \pm 0.4$ & $2.9 \pm 0.4$ & $3.0 \pm 0.4$ & 0.15 \\
\hline Total stent length, $\mathrm{mm}$ & $23(15-32)$ & $24(15-33)$ & $20(15-32)$ & 0.25 \\
\hline \multicolumn{5}{|l|}{ Medications } \\
\hline Beta blocker, $n(\%)$ & $96(47.8)$ & $39(53.4)$ & $57(44.5)$ & 0.22 \\
\hline $\mathrm{CCB}^{10}, n(\%)$ & $105(52.2)$ & $34(46.6)$ & $71(55.5)$ & 0.22 \\
\hline $\mathrm{ACEI} / \mathrm{ARB}^{11}, n(\%)$ & $106(52.7)$ & $33(45.2)$ & $73(57.0)$ & 0.11 \\
\hline Statin type & & & & $<0.001$ \\
\hline Low-intensity statin, $n(\%)$ & $51(25.4)$ & $51(69.9)$ & $0(0)$ & \\
\hline Moderate-intensity statin, $n(\%)$ & $22(11.0)$ & $22(30.1)$ & $0(0)$ & \\
\hline High-intensity statin, $n(\%)$ & $0(0)$ & $0(0)$ & $0(0)$ & \\
\hline \multicolumn{5}{|l|}{ Labolatory findings } \\
\hline $\mathrm{TC}^{12}, \mathrm{mg} / \mathrm{dL}$ & $163.3 \pm 35.5$ & $158.9 \pm 34.7$ & $165.8 \pm 35.8$ & 0.18 \\
\hline $\mathrm{LDL}-\mathrm{C}^{13}, \mathrm{mg} / \mathrm{dL}$ & $96.9 \pm 30.3$ & $89.6 \pm 27.3$ & $101.0 \pm 31.3$ & 0.01 \\
\hline HDL-C ${ }^{14}, \mathrm{mg} / \mathrm{dL}$ & $42.6 \pm 14.0$ & $44.3 \pm 13.4$ & $41.6 \pm 14.2$ & 0.18 \\
\hline $\mathrm{TG}^{15}, \mathrm{mg} / \mathrm{dL}$ & $106.0(79.0-146.0)$ & $107.0(82.5-154.0)$ & $105.5(78.0-142.5)$ & 0.68 \\
\hline Non-FBG ${ }^{16}, \mathrm{mg} / \mathrm{dL}$ & $110.3 \pm 41.1$ & $104.5 \pm 27.5$ & $113.6 \pm 46.8$ & 0.13 \\
\hline Hemoglobin, g/dL & $10.6 \pm 1.5$ & $10.9 \pm 1.5$ & $10.5 \pm 1.4$ & 0.07 \\
\hline $\mathrm{HbA} 1 c^{17}, \%$ & $6.1 \pm 1.1$ & $6.1 \pm 1.0$ & $6.1 \pm 1.2$ & 0.87 \\
\hline $\mathrm{Ca}, \mathrm{mg} / \mathrm{dL}$ & $9.0 \pm 0.9$ & $9.0 \pm 1.0$ & $9.1 \pm 0.8$ & 0.83 \\
\hline $\mathrm{P}, \mathrm{mg} / \mathrm{dL}$ & $5.2 \pm 1.4$ & $5.0 \pm 1.4$ & $5.3 \pm 1.4$ & 0.28 \\
\hline hs-CRP ${ }^{18}, \mathrm{mg} / \mathrm{L}$ & $3.0(1.0-12.1)$ & $2.1(0.9-10.5)$ & $3.6(1.2-12.3)$ & 0.13 \\
\hline Albumin, mg/dL & $3.5 \pm 0.5$ & $3.6 \pm 0.4$ & $3.5 \pm 0.5$ & 0.18 \\
\hline $\mathrm{eGFR}^{19}, \mathrm{~mL} / \mathrm{min} / 1.73 \mathrm{~m}^{2}$ & $6.0 \pm 2.1$ & $6.0 \pm 2.1$ & $6.0 \pm 2.2$ & 0.97 \\
\hline
\end{tabular}

Abbreviations: ${ }^{1}:$ BMI, body mass index; ${ }^{2}: \mathrm{PCI}$, percutaneous coronary intervention; ${ }^{3}: \mathrm{CABG}$, coronary artery bypass grafting; ${ }^{4}$ : ACS, acute coronary syndrome; ${ }^{5}$ : RCA, right coronary artery; ${ }^{6}$ : LAD, left anterior descending coronary artery; ${ }^{7}$ : LCX, left circumflex coronary artery; ${ }^{8}$ : LMT, left main trunk coronary artery; ${ }^{9}: \mathrm{SVG}$, saphenous vein graft; ${ }^{10}$ : $\mathrm{CCB}$, calcium channel blocker; ${ }^{11}$ : $\mathrm{ACEI} / \mathrm{ARB}$, angiotensin-converting enzyme inhibitor/angiotensin receptor blocker; ${ }^{12}$ : TC, total cholesterol; ${ }^{13}$ : LDL-C, low density lipoprotein-cholesterol; ${ }^{14}$ : HDL-C, high density lipoprotein-cholesterol; ${ }^{15}$ : TG, triglycerides; ${ }^{16}$ : Non-FBG, non-fasting blood glucose; ${ }^{17}$ : HbA1c, glycated hemoglobin; ${ }^{18}$ : hs-CRP, high-sensitivity C-reactive protein; ${ }^{19}$ : eGFR, estimated glomerular filtration rate. 
3.2. Reduced Rates of Adverse Events Following PCI in Patients Receiving Statins, While There Was No Difference in Groups Divided by Preprocedural LDL-C Level

During the entire follow-up period, all-cause deaths occurred in 86 out of 201 patients (42.8\%), including $47 \mathrm{CV}$ deaths (23.4\%) and 39 non-CV deaths (19.4\%), and 3P-MACE were identified in 58 patients $(28.9 \%)$. Compared to the Non-statin group, the incidences per 1000 person-years of CV death, all-cause death and 3P-MACE were significantly lower in the Statin group, whereas those of non-CV death were not different in two groups (Table 2).

Table 2. Overall incidence of cardiovascular events (per 1000 person-years).

\begin{tabular}{ccccc}
\hline & $\begin{array}{c}\text { Overall } \\
(\boldsymbol{n}=\mathbf{2 0 1})\end{array}$ & $\begin{array}{c}\text { Statin } \\
(\boldsymbol{n}=\mathbf{7 3})\end{array}$ & $\begin{array}{c}\text { Non-Statin } \\
(\boldsymbol{n}=\mathbf{1 2 8})\end{array}$ & $p$-Value \\
\hline $\begin{array}{c}\text { All-cause death, } n \\
(/ 1000 \text { person-years })\end{array}$ & $86(107)$ & $19(64.7)$ & $67(131)$ & 0.001 \\
\hline $\begin{array}{c}\text { Cardiovascular death, } n \\
(/ 1000 \text { person-years })\end{array}$ & $47(58.3)$ & $8(27.2)$ & $39(76.2)$ & 0.002 \\
\hline $\begin{array}{c}\text { Non-cardiovascular death, } n \\
(/ 1000 \text { person-years })\end{array}$ & $39(48.4)$ & $11(37.4)$ & $28(54.7)$ & 0.24 \\
\hline $\begin{array}{c}\text { 3P-MACE }{ }^{1}, n \\
(/ 1000 \text { person-years })\end{array}$ & $58(77.0)$ & $12(43.7)$ & $46(96.1)$ & 0.003 \\
\hline
\end{tabular}

Abbreviations: ${ }^{1}$ : 3P-MACE, 3 point major adverse cardiovascular events.

Unadjusted Kaplan-Meier analyses followed by the log-rank comparison test consistently showed significantly lower cumulative cardiovascular-related and all-cause mortality rates, as well as a lower incidence of 3P-MACE in the Statin group ( $p=0.007,0.004$ and 0.016 by log-rank comparison, respectively) (Figure $1 \mathrm{~A}-\mathrm{C}$ ), while similar cumulative non-CV mortalities in both groups $(p=0.18)$ (Figure 1D).
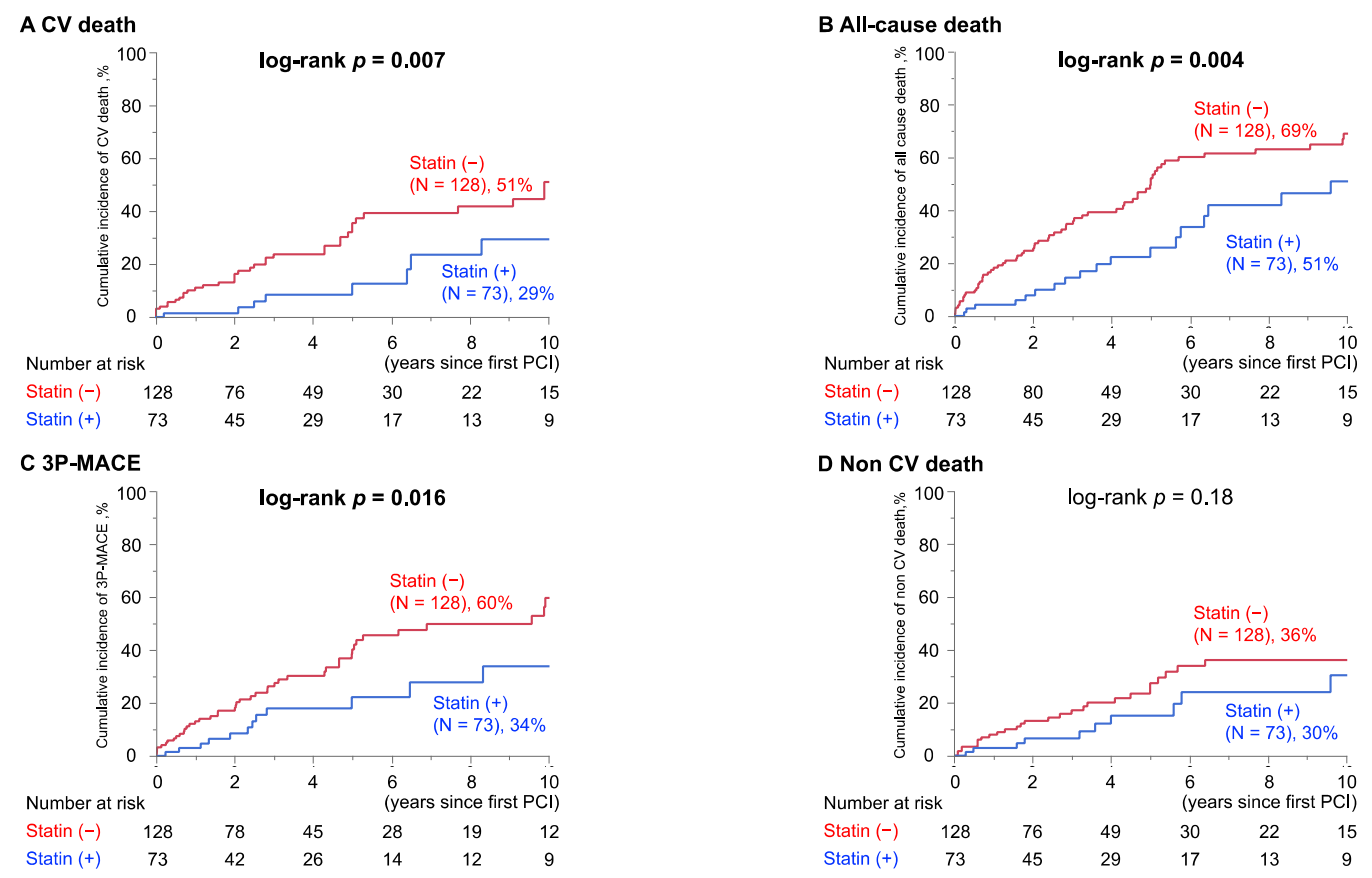

Figure 1. Cumulative cardiovascular event rates in groups with and without statins. Significantly reduced cumulative incidences of (A) CV death, (B) All-cause death, and (C) 3P-MACE were observed in patients with statin therapy at PCI, while no difference in (D) Non CV death was seen. Percent indicates the cumulative incidence of events at 10 years of follow-up in each group. 
In contrast, unadjusted Kaplan-Meier analysis revealed no significant difference in any cumulative incidences of CV (Figure 2A), all-cause (Figure 2B), 3P-MACE (Figure 2C) and non-CV mortalities (Figure 2D), when participants were divided by the median of LDL-C (93 mg/dL).
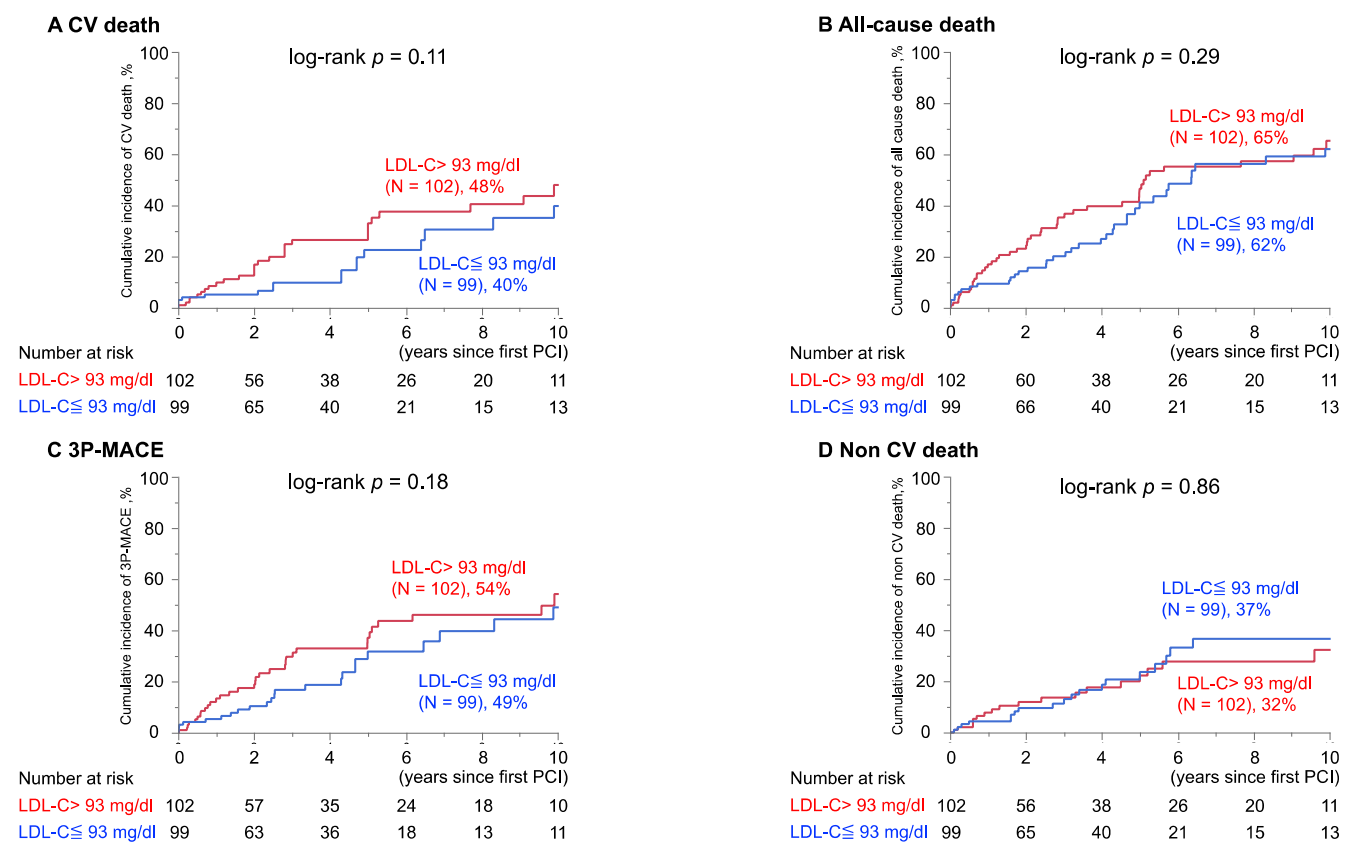

Figure 2. Cumulative cardiovascular event rates in groups divided by median LDL-C at procedure. Similar cumulative incidences of (A) CV death, (B) All-cause death, (C) 3P-MACE and (D) Non CV death in patients with and without LDL-C higher than median $(>93 \mathrm{mg} / \mathrm{dL})$. Percent indicates the cumulative incidence of events at 10 years of follow-up in each group.

\subsection{Adjusted Prognostic Impact of Statin Use for Outcomes Following PCI in Patients with Maintenance Hemodialysis}

To further address the prognostic effect of statin therapy in patients with chronic hemodialysis after PCI, univariate-unadjusted and multivariate-adjusted Cox proportional hazard analyses were used to calculate the hazard ratios (HRs) of statin therapy for CV death, all-cause death and 3P-MACE, respectively. Covariates included in the multivariate models are summarized in Supplementary Table S1. Most of the interactions among statin therapy and LDL-C in Models 2 and 3 for CV death, all-cause death and 3P-MACE were not significant $(p>0.05)$, except statin therapy and LDL-C in Model 3 for all-cause death $(p=0.01)$ (Supplementary Table S2). Univariate analysis showed that statin therapy was significantly associated with reduced risk of all endpoints (Supplementary Table S3). Multivariate analyses using a model including conventional risk factors in the population after PCI (Model 1) showed a substantial risk reduction by statin therapy for all endpoints (HR and 95\% confidence interval (CI) ( $p$-value) for CV death: 0.37, 0.16-0.75 (0.005), for all-cause death: $0.47,0.27-0.78$ (0.003) and for 3P-MACE: 0.46, 0.23-0.85 (0.01), respectively). Furthermore, analyses using a different model which additionally included receiving beta blockers at PCI and serum level of LDL-C (Model 2) calculated significantly reduced HRs for all endpoints comparable with Model 1. In a model that further included serum hs-CRP level in addition to the variates of Model 2 (Model 3), a risk reduction by statin therapy for $\mathrm{CV}$ death and all-cause death was observed, and it also showed the similar tendency for 3P-MACE, although the difference was not statistically significant $(0.53,0.26-1.00(0.05)$, respectively) (Figure 3). 

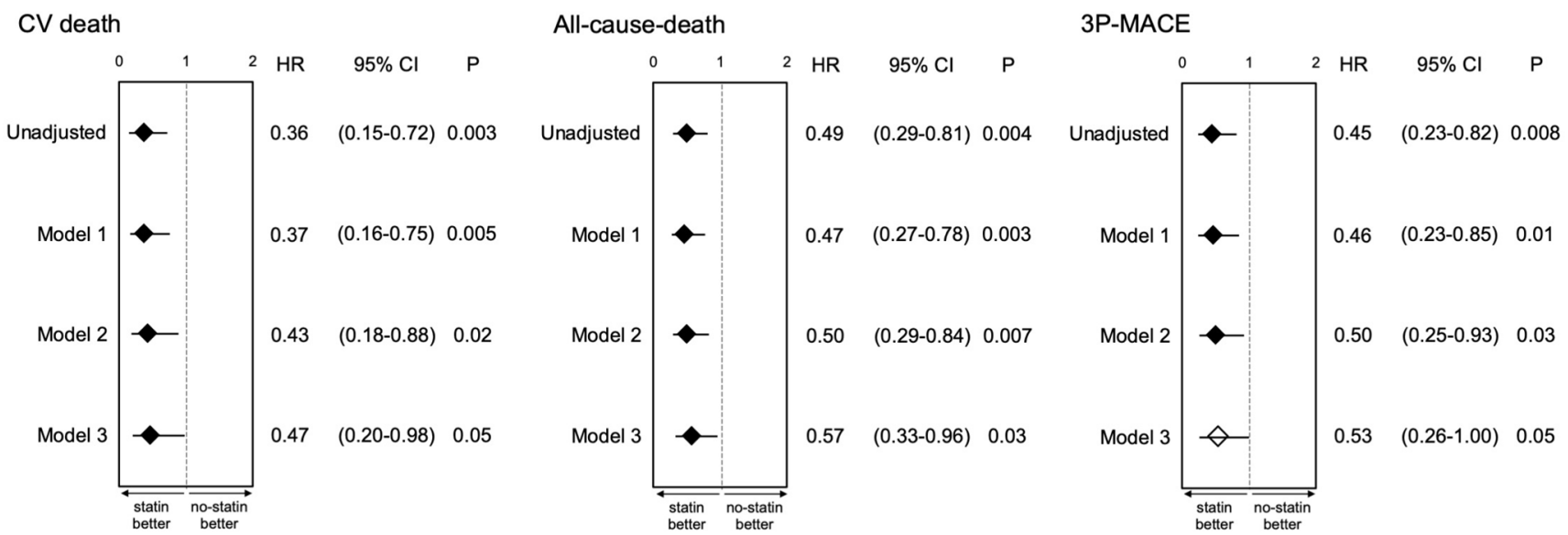

Figure 3. Hazard ratios of statins for cardiovascular events in hemodialysis patients following PCI. Hazard ratios of statin therapy at PCI for unadjusted and adjusted by 3 models. Closed and open rhombuses indicate significant $(p<0.05)$ and insignificant $(\geq 0.05)$ association of statin therapy with endpoints, respectively.

\section{Discussion}

The present observational study involving consecutive 201 patients with ESRD requiring hemodialysis who underwent PCI demonstrated that statin therapy at PCI was significantly associated with reduced risk of subsequent $\mathrm{CV}$ and all-cause mortalities and 3P-MACE, while it had no effect on non-CV mortalities. In contrast, the cumulative incidences of $C V$ death, all-cause death and 3P-MACE were similar in the two groups divided by the median LDL-C ( $93 \mathrm{mg} / \mathrm{dL})$. Furthermore, statins were associated with substantially reduced risk of $\mathrm{CV}$ death, all-cause death and 3P-MACE after adjusting for gender, age, diabetic nephropathy, BMI, receiving beta blockers, hs-CRP, and LDL-C level.

The number of patients with ESRD who are on chronic hemodialysis is increasing worldwide $[2,3,18]$. Although the age distribution trend indicates an increase in older patients among those with chronic hemodialysis, overall mortality has declined in the past 20 to 30 years $[2,19,20]$. The appropriate control of risk factors in patients with dialysis, such as blood pressure [21] and blood glucose [22], as well as the technical advancements in dialysis may have contributed to lowering the mortality in this population. Numerous lines of evidence have established the efficacy of statin therapy in the primary and secondary prevention of atherosclerotic $\mathrm{CV}$ diseases for the entire, and wide range of subpopulations at high risk, including those with CKD $[8,23]$. However, previous randomized trials and a meta-analysis of a dialysis population have shown little or no effect of statins for improving outcomes, and even if they have any favorable prognostic effect, the magnitude of the relative reduction of statins in the ESRD population appears to be substantially smaller than in those who are in earlier stages of CKD [9-11,24]. Accordingly, current guidelines of lipid management have recommended that statin therapy should not to be initiated for patients with ESRD requiring dialysis $[12,16,17,25]$. Moreover, there is a paucity of data regarding whether statins have merit in the population of patients with both ESRD on dialysis and with established $\mathrm{CAD}$ and who underwent coronary revascularization. Many of the randomized $\mathrm{CV}$ outcome trials of statins for the secondary prevention of coronary artery disease have excluded individuals with dialysis $[26,27]$, and the number of patients who had a history of coronary revascularization in previous statin trials involving dialysis patients was limited (13\% in $4 \mathrm{D}$ and $6.2 \%$ in AURORA) $[9,10]$. Additionally, there is an emerging concern that statins might enhance arterial calcification in patients with CKD [28,29]. Conversely, several observational studies utilizing a large-scale registry database have reported the continuation of statin therapy through the induction of maintenance dialysis in patients with ESRD was associated with lower all-cause and CV mortality rates, compared to individuals in whom it was discontinued through the pre- to post-dialysis stages $[30,31]$. 
Accordingly, despite no recommendation concerning the initiation of statins, guidelines paradoxically encourage the continuation of statins in patients who were already receiving them before the introduction of dialysis $[12,16,17,25]$. Regarding patients with both ESRD and $\mathrm{CAD}$, two observational studies from east Asia have indicated a prognostic merit of statins is to reduce the risk of all-cause mortality following myocardial infarction [32] and the composite of non-fatal myocardial infarction, stroke and all-cause mortality following PCI [33]. However, the overall quality of evidence to guide a therapeutic strategy in this specific population is still insufficient, although the rates of mortality and adverse $\mathrm{CV}$ events following PCI are extremely high [34-36]. The present study showed the significant prognostic merit of statin therapy since it was associated with reduced risk of $\mathrm{CV}$ and all-cause mortality and 3P-MACE following PCI. Moreover, we evaluated the merit of statins in this population in light of LDL-C, a main target of statins, which has rarely been assessed thus far [32,33]. In the present study, the Kaplan-Meier curves of groups with and without high LDL-C (> and $\leq$ median, $93 \mathrm{mg} / \mathrm{dL}$ ) were not significantly different. In multivariate Cox proportional hazard analyses, the significant risk reduction by statins was maintained, when it was adjusted by LDL-C level for all endpoints. These findings suggest that the prognostic merit of statins was not mainly mediated by LDL-C lowering property of statins. Moreover, the prognostic impact of statins was further adjusted by using multivariate models including previously established risk factors in the population of the present study, such as reduced BMI and elevated hs-CRP, corresponding to poor nutritional status [37,38] and continuous systemic inflammation [39], respectively [40-42]. Even after adjustment for these risk factors, the prognostic merit of statins in this study for all three endpoints remained significant. Taken together, our findings indicated that statins might be effective for better long-term outcomes in ESRD patients complicated by CAD, and the benefit was not mainly mediated by its LDL-C lowering property. Accordingly, the overall findings of this study may suggest the need to encourage not only continuing, but also initiating, statin therapy in dialysis patients complicated by CAD. The significance of this study which might add novel evidence, not negate previous findings, is that there is a prognostic merit of statins in the specific population of maintenance HD complicated by established CAD and the benefit was through the mechanism other than LDL-C lowering property of statins.

This study has several limitations. First, since it was retrospective in nature due to its analysis of a single center prospective registry database involving a relatively small number of participants without any randomization, and unaccounted confounding factors, which were not recorded or were not even included in the model, may potentially induce bias, although we have adjusted for known confounding factors. Second, the duration and dose of the statin pretreatment before the PCI procedure were not determined, and they may have had dominant effects on the outcomes in this population. Third, the adverse effects of statin treatments were not evaluated in detail. Despite these limitations, the evaluation of the cause of death, patient background data including blood sampling data, such as LDL-C and hs-CRP, and the long-term follow-up period have strengthened the significance of the findings of the present study.

\section{Conclusions}

The present study has shown that statin administration was significantly associated with better outcomes in patients with ESRD on chronic hemodialysis following PCI. Although the mechanisms of the prognostic merit of statins are yet to be elucidated, the study results indicate that it might be independent from LDL-C lowering property of statins.

Supplementary Materials: The following supporting information can be downloaded at: https: / / www.mdpi.com/article/10.3390/jcm11020390/s1, Table S1: Covariates included in the models of multivariate Cox proportional hazard analyses, Table S2: Interactions among statin therapy and LDLC, Table S3: Univariate-unadjusted Cox proportional hazard analysis for predicting cardiovascular mortality, all-cause mortality and 3P-MACE, Figure S1: Consort diagram of the present study. 


\begin{abstract}
Author Contributions: Conceptualization, T.F. and H.I.; methodology, T.F. and H.I.; formal analysis, T.F. and H.I.; data curation, T.F., Y.C., S.D., H.E., H.W., R.N., M.O., Y.K., I.O., T.D., T.K. and K.I.; writing—original draft preparation, T.F.; writing—review and editing, H.I.; supervision, H.I., S.O., K.M. and T.M.; funding acquisition, H.I. All authors have read and agreed to the published version of the manuscript.
\end{abstract}

Funding: This study was supported by a Grant-in-Aid for Scientific Research from the Ministry of Education, Culture, Sports, Science and Technology of Japan for HI (18K08049) and Grant-in-Aid for Scientific Research from Japan Society for the Promotion of Science for TF (21K16066).

Institutional Review Board Statement: The study was performed in accordance with the Declaration of Helsinki and with approval from the Institutional Review Board (IRB) of Juntendo University (IRB number: 17-170).

Informed Consent Statement: Informed consent was obtained from all subjects involved in the study.

Data Availability Statement: Data available on request due to restrictions, e.g., privacy or ethical.

Acknowledgments: The authors wish to thank Yumi Nozawa for her excellent assistance with the data collection and maintenance of the J-PACT registry database.

Conflicts of Interest: The authors declare no conflict of interest.

\title{
References
}

1. Bikbov, B.; Purcell, C.A.; Levey, A.S.; Smith, M.; Abdoli, A.; Abebe, M.; Adebayo, O.M.; Afarideh, M.; Agarwal, S.K.; Agudelo-Botero, M.; et al. Global, regional, and national burden of chronic kidney disease, 1990-2017: A systematic analysis for the Global Burden of Disease Study 2017. Lancet 2020, 395, 709-733. [CrossRef]

2. Saran, R.; Robinson, B.; Abbott, K.C.; Bragg-Gresham, J.; Chen, X.; Gipson, D.; Gu, H.; Hirth, R.A.; Hutton, D.; Jin, Y.; et al. US Renal Data System 2019 Annual Data Report: Epidemiology of Kidney Disease in the United States. Am. J. Kidney Dis. 2020, 75, A6-A7. [CrossRef]

3. Kramer, A.; Boenink, R.; Noordzij, M.; Bosdriesz, J.R.; Stel, V.S.; Beltran, P.; Ruiz, J.C.; Seyahi, N.; Comas Farnes, J.; Stendahl, M.; et al. The ERA-EDTA Registry Annual Report 2017: A summary. Clin. Kidney J. 2020, 13, 693-709. [CrossRef] [PubMed]

4. Go, A.S.; Chertow, G.M.; Fan, D.; McCulloch, C.E.; Hsu, C.Y. Chronic kidney disease and the risks of death, cardiovascular events, and hospitalization. N. Engl. J. Med. 2004, 351, 1296-1305. [CrossRef] [PubMed]

5. Stirnadel-Farrant, H.A.; Karaboyas, A.; Cizman, B.; Bieber, B.A.; Kler, L.; Jones, D.; Cobitz, A.R.; Robinson, B.M. Cardiovascular Event Rates among Hemodialysis Patients Across Geographical Regions-A Snapshot From The Dialysis Outcomes and Practice Patterns Study (DOPPS). Kidney Int. Rep. 2019, 4, 864-872. [CrossRef]

6. Joki, N.; Hase, H.; Nakamura, R.; Yamaguchi, T. Onset of coronary artery disease prior to initiation of haemodialysis in patients with end-stage renal disease. Nephrol. Dial. Transplant. 1997, 12, 718-723. [CrossRef] [PubMed]

7. Otsuka, Y.; Ishiwata, S.; Inada, T.; Kanno, H.; Kyo, E.; Hayashi, Y.; Fujita, H.; Michishita, I. Comparison of haemodialysis patients and non-haemodialysis patients with respect to clinical characteristics and 3-year clinical outcomes after sirolimus-eluting stent implantation: Insights from the Japan multi-centre post-marketing surveillance registry. Eur. Heart J. 2011, 32, 829-837. [CrossRef]

8. Cholesterol Treatment Trialists' (CTT) Collaboration. Efficacy and safety of LDL-lowering therapy among men and women: Meta-analysis of individual data from 174,000 participants in 27 randomised trials. Lancet 2015, 385, 1397-1405. [CrossRef]

9. Wanner, C.; Krane, V.; März, W.; Olschewski, M.; Mann, J.F.; Ruf, G.; Ritz, E. Atorvastatin in patients with type 2 diabetes mellitus undergoing hemodialysis. N. Engl. J. Med. 2005, 353, 238-248. [CrossRef] [PubMed]

10. Fellström, B.C.; Jardine, A.G.; Schmieder, R.E.; Holdaas, H.; Bannister, K.; Beutler, J. Rosuvastatin and cardiovascular events in patients undergoing hemodialysis. N. Engl. J. Med. 2009, 360, 1395-1407. [CrossRef] [PubMed]

11. Baigent, C.; Landray, M.J.; Reith, C.; Emberson, J.; Wheeler, D.C.; Tomson, C.; Wanner, C.; Krane, V.; Cass, A.; Craig, J.; et al. The effects of lowering LDL cholesterol with simvastatin plus ezetimibe in patients with chronic kidney disease (Study of Heart and Renal Protection): A randomised placebo-controlled trial. Lancet 2011, 377, 2181-2192. [CrossRef]

12. Wanner, C.; Tonelli, M. KDIGO Clinical Practice Guideline for Lipid Management in CKD: Summary of recommendation statements and clinical approach to the patient. Kidney Int. 2014, 85, 1303-1309. [CrossRef]

13. Hick, K.A.; Mahaffey, K.W.; Mehran, R.; Nissen, S.E.; Wiviott, S.D.; Dunn, B.; Solomon, S.D.; Marler, J.R.; Teerlink, J.R.; Farb, A.; et al. 2017 Cardiovascular and Stroke Endpoint Definitions for Clinical Trials. Circulation 2018, 137, 961-972. [CrossRef]

14. Eknoyan, G.; Beck, G.J.; Cheung, A.K.; Daugirdas, J.T.; Greene, T.; Kusek, J.W.; Dwyer, J.T. Effect of dialysis dose and membrane flux in maintenance hemodialysis. N. Engl. J. Med. 2002, 347, 2010-2019. [CrossRef] [PubMed]

15. Schneider, A.; Jardine, A.G.; Schneider, M.P.; Holdaas, H.; Holme, I.; Fellstroem, B.C.; Zannad, F.; Schmieder, R.E.; AURORA Study Group. Determinants of cardiovascular risk in haemodialysis patients: Post hoc analyses of the AURORA study. Am. J. Nephrol. 2013, 37, 144-151. [CrossRef] 
16. Grundy, S.M.; Stone, N.J.; Bailey, A.L.; Beam, C.; Birtcher, K.K.; Blumenthal, R.S.; Braun, L.T.; de Ferranti, S.; Faiella-Tommasino, J.; Forman, D.E.; et al. 2018 AHA/ACC/AACVPR/AAPA/ABC/ACPM/ADA/AGS/APhA/ASPC/NLA/PCNA Guideline on the Management of Blood Cholesterol: A Report of the American College of Cardiology/American Heart Association Task Force on Clinical Practice Guidelines. Circulation 2019, 139, e1082-e1143. [CrossRef]

17. Mach, F.; Baigent, C.; Catapano, A.L.; Koskinas, K.C.; Casula, M.; Badimon, L.; Chapman, M.J.; De Backer, G.G.; Delgado, V.; Ference, B.A.; et al. 2019 ESC/EAS Guidelines for the management of dyslipidaemias: Lipid modification to reduce cardiovascular risk. Eur. Heart J. 2020, 41, 111-188. [CrossRef] [PubMed]

18. Nitta, K.; Goto, S.; Masakane, I.; Hanafusa, N.; Taniguchi, M.; Hasegawa, T.; Nakai, S.; Wada, A.; Hamano, T.; Hoshino, J.; et al. Annual dialysis data report for 2018, JSDT Renal Data Registry: Survey methods, facility data, incidence, prevalence, and mortality. Ren. Replace. Ther. 2020, 6, 41. [CrossRef]

19. Hanafusa, N.; Nakai, S.; Iseki, K.; Tsubakihara, Y. Japanese society for dialysis therapy renal data registry-a window through which we can view the details of Japanese dialysis population. Kidney Int. Suppl. 2015, 5, 15-22. [CrossRef]

20. Foster, B.J.; Mitsnefes, M.M.; Dahhou, M.; Zhang, X.; Laskin, B.L. Changes in Excess Mortality from End Stage Renal Disease in the United States from 1995 to 2013. Clin. J. Am. Soc. Nephrol. 2018, 13, 91-99. [CrossRef] [PubMed]

21. Agarwal, R. Blood pressure and mortality among hemodialysis patients. Hypertension 2010, 55, 762-768. [CrossRef] [PubMed]

22. Ricks, J.; Molnar, M.Z.; Kovesdy, C.P.; Shah, A.; Nissenson, A.R.; Williams, M.; Kalantar-Zadeh, K. Glycemic control and cardiovascular mortality in hemodialysis patients with diabetes: A 6-year cohort study. Diabetes 2012, 61, 708-715. [CrossRef] [PubMed]

23. Baigent, C.; Blackwell, L.; Emberson, J.; Holland, L.E.; Reith, C.; Bhala, N.; Collins, R. Efficacy and safety of more intensive lowering of LDL cholesterol: A meta-analysis of data from 170,000 participants in 26 randomised trials. Lancet 2010, 376, 1670-1681. [CrossRef] [PubMed]

24. Palmer, S.C.; Craig, J.C.; Navaneethan, S.D.; Tonelli, M.; Pellegrini, F.; Strippoli, G.F. Benefits and harms of statin therapy for persons with chronic kidney disease: A systematic review and meta-analysis. Ann. Intern. Med. 2012, 157, 263-275. [CrossRef]

25. Tonelli, M.; Wanner, C. Lipid management in chronic kidney disease: Synopsis of the Kidney Disease: Improving Global Outcomes 2013 clinical practice guideline. Ann. Intern. Med. 2014, 160, 182-189. [CrossRef] [PubMed]

26. Miyauchi, K.; Kimura, T.; Shimokawa, H.; Daida, H.; Iimuro, S.; Iwata, H.; Ozaki, Y.; Sakuma, I.; Nakagawa, Y.; Hibi, K.; et al. Rationale and Design of Randomized Evaluation of Aggressive or Moderate Lipid Lowering Therapy with Pitavastatin in Coronary Artery Disease (REAL-CAD) Trial. Int. Heart J. 2018, 59, 315-320. [CrossRef]

27. Schwartz, G.G.; Oliver, M.F.; Ezekowitz, M.D.; Ganz, P.; Waters, D.; Kane, J.P.; Olsson, A.G. Rationale and design of the Myocardial Ischemia Reduction with Aggressive Cholesterol Lowering (MIRACL) study that evaluates atorvastatin in unstable angina pectoris and in non-Q-wave acute myocardial infarction. Am. J. Cardiol. 1998, 81, 578-581. [CrossRef]

28. De Vriese, A.S. Should Statins Be Banned from Dialysis? J. Am. Soc. Nephrol. 2017, 28, 1675-1676. [CrossRef]

29. Puri, R.; Nicholls, S.J.; Shao, M.; Kataoka, Y.; Uno, K.; Kapadia, S.R.; Tuzcu, E.M.; Nissen, S.E. Impact of statins on serial coronary calcification during atheroma progression and regression. J. Am. Coll. Cardiol. 2015, 65, 1273-1282. [CrossRef]

30. Streja, E.; Gosmanova, E.O.; Molnar, M.Z.; Soohoo, M.; Moradi, H.; Potukuchi, P.K.; Kalantar-Zadeh, K.; Kovesdy, C.P. Association of Continuation of Statin Therapy Initiated Before Transition to Chronic Dialysis Therapy With Mortality After Dialysis Initiation. JAMA Netw. Open 2018, 1, e182311. [CrossRef]

31. Soohoo, M.; Moradi, H.; Obi, Y.; Rhee, C.M.; Gosmanova, E.O.; Molnar, M.Z.; Kashyap, M.L.; Gillen, D.L.; Kovesdy, C.P.; Kalantar-Zadeh, K.; et al. Statin Therapy Before Transition to End-Stage Renal Disease With Posttransition Outcomes. J. Am. Heart Assoc. 2019, 8, e011869. [CrossRef] [PubMed]

32. Chung, C.M.; Lin, M.S.; Chang, C.H.; Cheng, H.W.; Chang, S.T.; Wang, P.C.; Chang, H.Y.; Lin, Y.S. Moderate to high intensity statin in dialysis patients after acute myocardial infarction: A national cohort study in Asia. Atherosclerosis 2017, 267, 158-166. [CrossRef] [PubMed]

33. Kim, S.H.; Jeong, H.Y.; Yang, D.H.; Kim, J.; Lee, S.Y. Beneficial effect of statins in patients receiving chronic hemodialysis following percutaneous coronary intervention: A nationwide retrospective cohort study. Sci. Rep. 2018, 8, 9692. [CrossRef] [PubMed]

34. Herzog, C.A.; Ma, J.Z.; Collins, A.J. Poor long-term survival after acute myocardial infarction among patients on long-term dialysis. N. Engl. J. Med. 1998, 339, 799-805. [CrossRef] [PubMed]

35. Shroff, G.R.; Solid, C.A.; Herzog, C.A. Long-term survival and repeat coronary revascularization in dialysis patients after surgical and percutaneous coronary revascularization with drug-eluting and bare metal stents in the United States. Circulation 2013, 127, 1861-1869. [CrossRef] [PubMed]

36. Chang, T.I.; Montez-Rath, M.E.; Tsai, T.T.; Hlatky, M.A.; Winkelmayer, W.C. Drug-Eluting Versus Bare-Metal Stents During PCI in Patients With End-Stage Renal Disease on Dialysis. J. Am. Coll. Cardiol. 2016, 67, 1459-1469. [CrossRef]

37. Stratton, R.J.; Hackston, A.; Longmore, D.; Dixon, R.; Price, S.; Stroud, M.; King, C.; Elia, M. Malnutrition in hospital outpatients and inpatients: Prevalence, concurrent validity and ease of use of the 'malnutrition universal screening tool' ('MUST') for adults. Br. J. Nutr. 2004, 92, 799-808. [CrossRef]

38. Cederholm, T.; Bosaeus, I.; Barazzoni, R.; Bauer, J.; Van Gossum, A.; Klek, S.; Muscaritoli, M.; Nyulasi, I.; Ockenga, J.; Schneider, S.M.; et al. Diagnostic criteria for malnutrition-An ESPEN Consensus Statement. Clin. Nutr. 2015, 34, 335-340. [CrossRef] 
39. Pearson, T.A.; Mensah, G.A.; Alexander, R.W.; Anderson, J.L.; Cannon, R.O., 3rd; Criqui, M.; Fadl, Y.Y.; Fortmann, S.P.; Hong, Y.; Myers, G.L.; et al. Markers of inflammation and cardiovascular disease: Application to clinical and public health practice: A statement for healthcare professionals from the Centers for Disease Control and Prevention and the American Heart Association. Circulation 2003, 107, 499-511. [CrossRef]

40. Beddhu, S.; Pappas, L.M.; Ramkumar, N.; Samore, M.H. Malnutrition and atherosclerosis in dialysis patients. J. Am. Soc. Nephrol. 2004, 15, 733-742. [CrossRef]

41. Qureshi, A.R.; Alvestrand, A.; Divino-Filho, J.C.; Gutierrez, A.; Heimbürger, O.; Lindholm, B.; Bergström, J. Inflammation, malnutrition, and cardiac disease as predictors of mortality in hemodialysis patients. J. Am. Soc. Nephrol. 2002, 13, S28-S36. [CrossRef] [PubMed]

42. den Elzen, W.P.; van Manen, J.G.; Boeschoten, E.W.; Krediet, R.T.; Dekker, F.W. The effect of single and repeatedly high concentrations of C-reactive protein on cardiovascular and non-cardiovascular mortality in patients starting with dialysis. Nephrol. Dial. Transplant. 2006, 21, 1588-1595. [CrossRef] [PubMed] 